\title{
PAPER
}

\section{Genetic testing for polyposis: practical and ethical aspects}

\section{H J Järvinen}

Gut 2003;52(Suppl II):ii 19-ii22

The three autosomal dominant inherited polyposis syndromes, familial adenomatous polyposis, juvenile polyposis, and Peutz-Jeghers polyposis predispose to colorectal cancer as does hereditary non-polyposis colorectal cancer syndrome. Uncovering the genetic background of these four cancer traits provides the possibility for genetic testing of the family members of an affected patient. Before testing identification of the underlying family specific pathogenic mutation is mandatory. This is possible in about $60 \%$ to $95 \%$ of families. Endoscopic surveillance can be safely discontinued in mutation negative family members and surveillance or prophylactic surgery can be targeted to mutation positive members alone. Testing requires genetic counselling and written informed consent to prevent misunderstanding and to minimise untoward effects such as anxiety. Permanent surveillance and adequate prophylactic treatment for all mutation positive subjects and families is best ensured in national or regional polyposis registries with the capacity to take care of long term follow up from generation to generation.

Correspondence to: Professor H J Järvinen, Department of Surgery, Helsinki University Centra Hospital, FIN-00029 HUS, Helsinki, Finland. heikki.jarvinen@hus.fi
$\mathrm{T}$ here are three main polyposis syndromes that share the features of autosomal dominant mode of inheritance and an increased risk of gastrointestinal cancer, especially colorectal cancer: (1) familial adenomatous polyposis (FAP), (2) juvenile polyposis (JP), and (3) Peutz-Jeghers polyposis (P-JP). A fourth closely related autosomal dominant trait is hereditary non-polyposis colorectal cancer syndrome (HNPCC). It has several clinical and genetic aspects in common with the polyposis syndromes, but also some important differences, considering the clinical management and cancer prevention measures available on the basis of the hereditary nature of these cancer predisposition conditions.

The molecular genetic background of the three polyposis syndromes and HNPCC were largely uncovered during the past 15 years. The first step was the localisation of the adenomatous polyposis coli (APC) gene on chromosome $5 \mathrm{q}^{1}$ followed by the characterisation of the gene in 1991. ${ }^{2}$ Two years later two genes associated with the HNPCC susceptibility were localised and later identified ${ }^{34}$ and followed by discovery of further DNA mismatch repair genes with proved or suspected association with the HNPCC syndrome. ${ }^{56}$ Lastly, the genes responsible for a major part of families with JP and P-J P were discovered ${ }^{7-9}$ (table 1).
The discovery of the genetic causation of the polyposis syndromes and HNPCC offers the possibility for predictive genetic testing of the descendants of the affected family members who have the theoretical risk of $50 \%$ of carrying the pathogenic mutation. The test can relieve the unaffected half of the family members from the cancer threat, endoscopic surveillance, and anxiety involved. On the other hand, the mutation positive family members can be identified with certainty, and appropriate clinical surveillance and prophylactic treatment can be offered for them to ensure optimal cancer prevention. The strategies of prevention and their efficacy vary in the four conditions, and many clinical and genetic problems still await for adequate solution. This review gives some guidelines for the management of polyposis and HNPCC families with the advent of predictive genetic testing.

\section{CLINICAL FEATURES AND THE CANCER RISK IN POLYPOSIS SYNDROMES AND HNPCC \\ Familial adenomatous polyposis MIM} (Mendelian inheritance in man) no 175100, FAP and Gardner syndrome; 276300, Turcot syndrome

FAP is characterised by multiple adenomatous polyps that tend to progress to adenocarcinoma In classic FAP the number of polyps is 100 at least ${ }^{10}$ but an attenuated form has been distinquished with a fewer number of adenomas. Turcot syndrome is a variant associated with a brain tumour, medulloblastoma. The estimated incidence of FAP varies around 1 per 10000 newborns or from 1 to 2 per 1000000 per annum. ${ }^{11}$ Between $30 \%$ to $50 \%$ of new patients are solitary cases probably representing new mutations of the APC gene. Mutations of this gene located in the long arm of chromosome $5(5 q$ 21-22) cause the disease. ${ }^{212}$

The clinical diagnosis of FAP requires demonstration of 100 colorectal adenomas. Histological examination of several adenomas is necessary. In the context of a definite family history the detection of fewer adenomas is sufficient as well as in the case of an attenuated disease form. Final diagnosis is achieved by discovery of a mutated APC gene but the detection rate has been about $60 \%$ to $95 \%$ of all FAP families. Well known extracolonic manifestations of the disease such as epidermoid cysts, osteomas of the jaws, desmoid

Abbreviations: APC, adenomatous polyposis coli (gene) FAP, familial adenomatous polyposis; HNPCC, hereditary non-polyposis colorectal cancer; JP, juvenile polyposis; MIM Mendelian inheritance in man; P-JP, Peutz-Jeghers polyposis 
Table 1 Genetic background of polyposis syndromes and HNPCC

\begin{tabular}{llll}
\hline Disease & Chromosome & Gene(s) & Discovered (ref) \\
\hline FAP & $5 q 21$ & APC & $\begin{array}{l}\text { Bodmer et al 1987 (1) } \\
\text { Groden et al 1991 (2) }\end{array}$ \\
JP & $18 q 21$ & SMAD4/DPC4 & Howe et al 1998 (8) \\
& $10 q 21-22$ & BMPR1A/ALK3 & Howe et al 2001 (9) \\
P-JP & $19 p 13.3$ & LKB1 & Hemminki et al 1998 (7) \\
HNPCC & $2 \mathrm{p} 21-23$ & MSH2 & Peltomäki et al 1993 (3) \\
& $3 \mathrm{p} 21$ & MLH1 & Lindblom et al 1993 (4) \\
& $2 \mathrm{p} 16$ & MSH6 & Miyaki et al 1997 (6) \\
\hline
\end{tabular}

tumours, gastric fundic gland polyps, or congenital hypertrophy of the retinal pigment epithelium may give additional diagnostic support. ${ }^{1}$

The most important clinical feature in FAP is the almost inevitable progression of one or more colorectal adenomas to cancer. The adenomas become detectable at puberty, symptoms (bleeding, diarrhoea) appear gradually in early adulthood, and the mean age of cancer occurrence is about 40 years. ${ }^{101213}$ If FAP is diagnosed on the basis of symptoms cancer is present at the time of diagnosis in about $60 \%$ of patients. However, endoscopic screening on the basis of family history can give the diagnosis practically always before the development of cancer. This requires examination of all children of an affected parent starting at the age of 12 to 15 years at intervals of a few years. Endoscopic screening can be replaced by mutation testing in families with a known pathogenic APC mutation. Mutation positive members alone need subsequent endoscopic surveillance to detect colorectal adenoma development.

The prophylactic treatment of FAP is colectomy. There is still discussion whether colectomy with ileorectal anastomosis is acceptable because it leaves a definite risk of rectal stump carcinoma reaching $15 \%$ to $25 \%$ within 20 to 25 years. ${ }^{14}{ }^{15}$ Many authors favour proctocolectomy with ileal pouch-anal anastomosis in most cases even despite the risk of less perfect anal function than after ileorectal anastomosis. ${ }^{14}{ }^{16}$ Further morbidity and mortality may occur due to desmoid tumours and duodenal adenomas and cancer. In general, early diagnosis of FAP and proper prophylactic treatment offers an excellent long term outcome comparable to that of the general population for about 20 years. ${ }^{17}$

\section{Juvenile polyposis}

MIM no 174900, 175050

JP is characterised by multiple juvenile polyps of the colorectum but also involving the stomach and the small intestine. ${ }^{18}$ The polyps are hamartomatous exhibiting cystic glands and hyperplastic stroma with inflammation. Large polyps are commonly lobulated and adenomatous dysplasia occurs in half of these atypical juvenile polyps giving rise to the increased risk of colorectal cancer. The cumulative cancer risk in JP has been estimated up to $30 \%$ or $50 \%$ in the colorectum and some $10 \%$ in the upper gastrointestinal tract. ${ }^{19} 20$

The number of juvenile polyps is usually less than the number of adenomas in FAP, often between 50 and 200 in the colon, but some patients have only few polyps. Gastric, duodenal, and small intestinal polyps occur in variable numbers in half of the patients. ${ }^{21}$ The syndrome is about 10 -fold less common than FAP with a frequency of 1 per 100000 newborns only. The syndrome is caused by mutations of at least two separate genes, SMAD4/DPC4 in chromosome 18q21 or BMPRIA/ALK3 in chromosome 10q $21-22 .{ }^{8}{ }^{9}$

The treatment of JP consists of repeated endoscopic removal of all polyps detectable in the colorectum and upper gastrointestinal tract. In cases with a great number of polyps in the colon colectomy with ileorectal anastomosis is advised. ${ }^{21}$ The treatment aims besides decreasing the cancer risk involved preventing the development of symptoms such as bleeding, anaemia, and diarrhoea.

\section{Peutz-Jeghers polyposis}

MIM no 175200

P-JP is characterised by mucocutaneous melanin pigmentation and hamartomatous intestinal polyposis. The polyps affect preferentially the small intestine but they occur in the stomach and large intestine also. Peutz-Jeghers syndrome is caused by mutations of the LKBl gene on the short arm of chromosome 19, 19p 13.3. ${ }^{7}$ The incidence of P-JP is of the same range as observed in JP, probably about 1 per 100000 newborns. The polyps are originally hamartomas but epithelial dysplasia has been demonstrated to develop rarely and adenocarcinoma may occur in contiguity with the PeutzJeghers polyp. ${ }^{22-24}$ Consequently, there is an 80 -fold to 500 -fold excess of gastrointestinal cancer in the P-JP syndrome. ${ }^{25}$

Since the recognition of the cancer risk involved in P-JP, endoscopic surveillance with polypectomies has been recommended for the affected patients by two year intervals using both upper gastrointestinal and colonoscopic approaches ("top and tail endoscopy"26). Unfortunately, the small bowel remains mainly beyond the reach of endoscopies. Therefore, at operations needed because of bleeding episodes or small bowel obstruction due to intussusception the entire small intestine should be cleared up from the polyps using intraoperative endoscopy and enterotomies. The problem of an excess of many non-gastrointestinal cancers such as breast, endometrial, ovarian, or lung cancer with risk ratios from 15 to 30 is difficult to cover with any simple preventive programme. ${ }^{22} 25$

\section{Hereditary non-polyposis colorectal cancer syndrome (HNPCC) \\ MIM no 120435-6}

HNPCC or Lynch syndrome is an autosomal dominant cancer predisposition syndrome without clear clinical signs preceding cancer except for solitary colorectal adenomas. The predominant tumours are colorectal and endometrial cancer. Several other cancer types are, however, also occurring in excess such as carcinoma of the stomach, ovary, ureter and renal pelvis, bile ducts, kidney, small intestine, and brain tumours. ${ }^{27}$ Mutations of three DNA mismatch repair genes have been associated with the HNPCC trait, MSH2, MLH1, and MSH6. ${ }^{3-6}$ The role of other mismatch repair genes (for example, PMS1, PMS2, and MSH3) is still under evaluation. ${ }^{28}$ HNPCC is more common than the polyposis syndromes and it explains up to $3 \%$ of all cases of colorectal cancer. ${ }^{29}$

Colon cancer develops at young age (mean 45 years), located predominantly in the proximal colon, and synchronous or metachronous second tumours occur in more than a third of patients. ${ }^{30}$ The DNA content of the tumours is diploid $^{31}$ and microsatellite instability is a characteristic feature. $^{32}$ In histological examination tumours exhibit high mucin content, Crohn's disease-like inflammatory reaction around, and the differentiation grade is commonly poor. ${ }^{33}$ The clinical or pathological features, however, are not specific and do not alone allow a diagnosis of HNPCC to be done. The family history has a central role in the identification. According to the Amsterdam criteria the following conditions should be fulfilled: (1) at least three patients with colorectal cancer of whom one is a first degree relative of the other two, (2) affected family members in two generations, at least, (3) at least one cancer patient should be diagnosed before the age of 50 years. The latest revision of these criteria accepts cancers of the endometrium, small intestine, or uroepithelium besides the colorectum. ${ }^{34}$

The cumulative cancer risk in HNPCC approaches about $80 \%$ and $60 \%$ for colorectal and endometrial cancers, 
respectively. The corresponding lifetime risks for other cancer types remain between $13 \%$ and $2 \% .{ }^{27}$ Cancer prevention in HNPCC consists of repeated colonoscopy with polypectomies at two to three year intervals and of endometrial suction biopsies possibly combined with endovaginal ultrasonography. ${ }^{35}$ Prophylactic surgery (colectomy, hysterectomy) remains an alternative in selected cases. Prevention and early detection of other tumour types is problematic because of their relative rarity and when there are no suitable screening methods.

\section{PREDICTIVE GENETIC TESTING}

The polyposis syndromes can be identified on the basis of their typical clinical features-that is, by demonstration of the intestinal polyps in endoscopy and their histological typing after polypectomies. This is the standard method in symptomatic patients who usually are the probands of a new family or solitary cases. Endoscopic screening of all first degree family members is consequently indicated to achieve early diagnosis before the development of cancer. In this evaluation the extracolonic manifestations of the disease, such as melanin pigmentation in P-JP or retinal pigmentation, epidermoid cysts or osteomas of the jaw in FAP, may offer additional clues.

Clinical screening, however, is unreliable depending on the age of the subject, severity of the polyposis associated with the particular mutation of the family, and the syndrome in question. There is variation in the phenotypic expression even between members of the same family affected with FAP. ${ }^{36}$ Some FAP families also present with late onset of adenomas and mild phenotype, attenuated FAP, often associated with APC gene mutations localised either in the 5' or 3' part of the gene or in exon $9 .{ }^{37}{ }^{38}$ Therefore, negative endoscopic findings at a certain age cannot exclude the possibility of later disease expression. The issue is even more difficult in HNPCC where there are no clear clinical indicators of the disease at all. Thus, knowledge of the pathogenic mutation can greatly help the organisation of family surveillance in polyposis syndromes. In HNPCC this knowledge is almost irreplaceable. Unfortunately, despite typical criteria of a specific polyposis syndrome or HNPCC the underlying mutation remains undetected in some $20 \%$ to $40 \%$ of families, as is shown in the data of the Finnish Polyposis and HNPCC Registry (table 2).

The first step towards the genetic testing is a reliable clinical and histopathological diagnosis. This makes it possible to direct the search for the pathogenic mutation into the appropriate gene(s). In HNPCC demonstration of microsatellite instability ${ }^{32}$ supports the existence of a mismatch repair gene mutation, and immunohistochemical demonstration of the expression of the mismatch repair proteins may indicate in which gene the mutation lies ${ }^{39}{ }^{40}$ directing further identification. Predictive genetic testing of the at risk family members is possible first after reliable identification of the specific mutation in a family. There are already examples of commercial gene tests with inappropriate use without knowledge of the underlying mutation, which have given misleading result. ${ }^{41}$

After identification of the pathogenic mutation the predictive testing of the family members has high accuracy, practically $100 \%$. Mutation positive subjects can accordingly

Table 2 Detection rate of pathogenic mutations in the Finnish Polyposis and HNPCC registry (December, 2001)

\begin{tabular}{lllll}
\hline & FAP (\%) & JP (\%) & P-JP (\%) & HNPCC (\%) \\
\hline Mutation detected & $57(77)$ & $6(75)$ & $7(54)$ & $92(77)$ \\
No mutation detected & 17 & 2 & 6 & 28 \\
Not examined & 31 & 4 & 2 & 20 \\
Families in total & 105 & 12 & 15 & 140 \\
\hline
\end{tabular}

be advised to appropriate surveillance or prophylactic treatment, while the follow up of the mutation negative subjects can be discontinued. Omission of endoscopic surveillance in half of the descendants correspondingly cuts the costs of family screening. Even though the cost of one mutation test of a known mutation (€550) is higher than a single sigmoidoscopy (€120) or colonoscopy (€320), the total costs are reduced when repeated endoscopies of mutation negative subjects become unnecessary. On the other hand, the cost of the search for a new germline mutation is considerably higher, about $€ 2500$. After all, the economic aspects of the genetic compared with endoscopic screening play a secondary part considering the far greater accuracy of genetic screening. It should be noted that the prices presented above reflect the situation in year 2001 at the Helsinki University Hospital. The prices vary with time and may be quite different elsewhere.

Mutation data have also been suggested to serve as a guide in the planning of prophylactic surgery or clinical surveillance. The idea comes from the observations about genotype phenotype correlation. In a Dutch series of FAP patients treated with colectomy and ileorectal anastomosis the patients with mutations 3' to codon 1250 had a higher rate of rectal cancer than those with mutations $5^{\prime}$ to this codon. ${ }^{42}$ It was thought that the choice of the method of surgery, colectomy with ileorectal anastomosis versus proctocolectomy with ileal pouch-anal anastomosis, should be determined on the basis of the APC gene mutation type. The genotype phenotype correlations, however, seem more complicated. For example, mild phenotype occurs in patients with mutations at each end of the APC gene or in exon $9,{ }^{37} 3843$ and other considerations such as the desmoid tumour tendency, partly determined by the mutation site, might also influence on decisions. ${ }^{43}$ At present, mutation analysis has limited value for surgical decisions in FAP and the clinical features of individual patients and families have a more central role.

\section{ETHICAL AND LEGAL ASPECTS OF GENETIC TESTING}

Recognition of a hereditary cancer syndrome in a family provokes anxiety in family members. The possibility of genetic testing for the diagnosis of mutation status of the relatives may cause ambivalent feelings. A mutation negative result naturally is reassuring but the finding of a pathogenic mutation may increase anxiety, even though it enables appropriate surveillance and treatment. In a recent study on predictive testing for at risk members of HNPCC families the anxiety scores expectedly increased in mutation carriers and decreased in mutation negative individuals, but the difference disappeared within one month. ${ }^{44}$ This result was obtained in the context of an well organised genetic counselling programme with a follow up for one year. Despite careful individual counselling the mutation positive subjects tended to misunderstand the significance of the test result and the consequent cancer risk quite often. ${ }^{45}$ The necessity of individual counselling and obtaining an informed consent for testing is clear because of possible untoward effects of testing even besides anxiety. There may also be effects on eligibility for insurance or employment even though there is common agreement that genetic testing should not cause discrimination and the test result should be kept entirely confidential. The practices in different countries considering insurance companies and employers may be different than in the European Union.

The appropriate age for testing depends on the average expression of the disease, which occurs already during teenagers in FAP and possibly earlier in P-JP and JP. In HNPCC the cancer incidence begins to rise significantly first after the age of 20 to 25 years, when the surveillance programme should start. At that age there is usually no problem in obtaining informed consent after genetic counselling. However, in FAP and other polyposis syndromes the information should be given to both 
children and their parents. In this context there may occur instances where an affected person does not permit information about the inherited condition to be distributed to other relatives or even to the children thus preventing the institution of the medically indicated cancer screening programme. Such a situation causes a serious ethical problem where repeated discussions may eventually give a solution.

The finding of a mutation positive result in polyposis or HNPCC causes the worry about organisation of permanent surveillance and proper prophylactic treatment throughout the rest of the life including screening and testing of all family members involved. An individual clinician faces many practical problems if the family is large and scattered around the country and even abroad. In such instance polyposis registries give the best quarantee of continued care of surveillance, genealogical examination, genetic counselling and testing, and even research cooperation. ${ }^{46}$ In maintenance of updated patient follow up data the registries need at present informed consent of the family members as has been provided by a European Union directive, the Personal Data Act. In many registries including the Finnish Polyposis and HNPCC Registry achieving a permanent position and independent financial status still awaits final solution, a problem that will hopefully be managed in near future considering the established excellent results in cancer prevention. ${ }^{17} 47$

\section{FUTURE DEVELOPMENT}

Knowledge about the genetic causation of the polyposis syndromes or HNPCC has thus far given not much hope for cure of the underlying genetic abnormality by gene therapy, for example, given the very short half time of the cells in the main target organ, intestinal epithelium. The only really curative treatment is induction of abortion after intrauterine molecular genetic diagnosis, a procedure that has not been taken in general use, thus far, despite its applicability. Increasing knowledge about the exact function of the genes involved may help in the development of targeted medical treatments, which normalise the disturbed function. Such development could at best obviate the need for prophylactic surgery or, at least, help in prevention of the poorly treatable extracolonic complications such as desmoid tumours or duodenal adenomas and cancer in FAP.

\section{REFERENCES}

1 Bodmer WF, Bailey CJ, Bodmer J, et al. Localization of the gene for familial adenomatous polyposis on chromosome 5 . Nature 1987;328:614-616.

2 Groden J, Thliveris A, Samowitz W, et al. Identification and characterization of the familial adenomatous polyposis coli gene. Cell 1991;66:589-600.

3 Peltomäki P, Aaltonen LA, Sistonen P, et al. Genetic mapping of a locus predisposing to human colorectal cancer. Science 1993;260: 810-12.

4 Lindblom A, Tannergård P, Werelius B, et al. Genetic mapping of a second locus predisposing to hereditary non-polyposis colon cancer. Nat Genet 1993;5:279-82.

5 Kinzler KW, Vogelstein B. Lessons from the hereditary colorectal cancer Cell 1996;87:159-70.

6 Miyaki M, Konishi M, Tanaka K, et al. Germline mutation of MSH6 as the cause of hereditary nonpolyposis colorectal cancer. Nat Genet 1997; 17:271-2

7 Hemminki A, Markie D, Tomlinson IPM, et al. A serine/threonine kinase gene defective in Peutz-Jeghers syndrome. Nature 1998;391:184-7.

8 Howe JR, Roth S, Ringold JC, et al. Mutations in the SMAD4/DPC4 gene in juvenile polyposis. Science 1998;280:1086-8.

9 Howe JR, Blair JA, Sayed MG et al. Germline mutations of BMPR IA in juvenile polyposis. Nat Genet $2001 ; 28: 184-7$

10 Bussey HJR. Familial polyposis coli. Family studies, histopathology, differential diagnosis and results of treatment. Baltimore: The Johns Hopkins University Press, 1975.

11 Bulow S, Holm NV, Hauge M. The incidence and prevalence of familia adenomatous polyposis in Denmark. Scand J Soc Med 1986;14:67-74.

12 Talbot IC, Burt R, Järvinen $\mathrm{H}$, et al. Familial adenomatous polyposis. In Hamilton SR, Aaltonen LA. Pathology and genetics of tumours of the digestive system. Lyon: IARC Press, 2000:120-5.

13 Järvinen HJ. Time and type of prophylactic surgery for familial adenomatosis coli. Ann Surg 1985;202:93-7.
14 Heiskanen I, Järvinen HJ. Fate of the rectal stump after colectomy and ileorectal anastomosis for familial adenomatous polyposis. Int $\mathrm{J}$ Colorectal Dis 1997; 12:9-13

15 Bulow C, Vasen HFA, Järvinen $\mathrm{H}$, et al. lleorectal anastomosis is appropriate for a subset of patients with familial adenomatous polyposis. Gastroenterology 2000:119:1454-60.

16 Kartheuser AH, Parc R, Penna CP, et al. lleal pouch-anal anastomosis as the first choice operation in patients with familial adenomatous polyposis: a ten-year experience. Surgery 1996;119:615-23.

17 Heiskanen I, Luostarinen T, Järvinen HJ. Impact of screening examinations on survival in familial adenomatous polyposis. Scand J Gastroenterol 2000;35:1284-7.

18 McColl I, Bussey HJR, Veale AM, et al. Juvenile polyposis coli. Proc $R$ Soc Med 1964;57:896-7

19 Jass JR, Williams CB, Bussey HJR, et al. Juvenile polyposis-a precancerous condition. Histopathology 1988;13:619-30.

20 Howe JR, Mitros FA, Summers RW, The risk of gastrointestinal carcinoma in familial juvenile polyposis. Ann Surg Oncol 1998;5:751-7.

21 Järvinen H. Juvenile gastrointestinal polyposis. Prob/ Gen Surg 1993; 10:749-57.

22 Hemminki A. The molecular basis and clinical aspects of Peutz-Jeghers syndrome. Cell Mol Life Sci 1999:55:735-50.

23 Spigelman AD, Murday V, Phillips RKS. Cancer and the Peutz-Jeghers syndrome. Gut 1989;30:1588-90.

24 Perzin KH, Bridge MF. Adenomatous and carcinomatous changes in hamartomatous polyps of the small intestine (Peutz-Jeghers syndrome): report of a case and review of the literature. Cancer 1982:49:971-83.

25 Giardiello FM, Brensinger JD, Tersmette AC, et al. Very high risk of cancer in familial Peutz-Jeghers syndrome. Gastroenterology 2000;1 19:1447-53

26 Phillips RKS, Spigelman AD, Thomson JPS. Familial adenomatous polyposis and other polyposis syndromes. London: Edward Arnold, 1994: 188-202

27 Aarnio M, Sankila R, Pukkala E, et al. Cancer risk in mutation carriers of DNA-mismatch repair genes. Int J Cancer 1999;81:214-18

28 Liu T, Yan H, Kuismanen S, et al. The role of hPMS1 and hPMS2 in predisposing to colorectal cancer. Cancer Res 2001;61:7798-802.

29 Salovaara R, Loukola A, Kristo P, et al. Population-based molecular detection of hereditary nonpolyposis colorectal cancer. J Clin Oncol 2000;18:2193-200.

30 Mecklin J-P, Järvinen HJ. Clinical features of colorectal carcinoma in cancer family syndrome. Dis Colon Rectum 1986;29:160-4.

31 Kouri M, Laasonen A, Mecklin J-P, et al. Diploid predominance in hereditary nonpolyposis colorectal carcinoma evaluated by flow cytometry. Cancer 1990;65: 1825-9.

32 Aaltonen LA, Peltomäki P, Leach FS, et al. Clues to the pathogenesis of familial colorectal cancer. Science 1993;260:812-16.

33 Shashidharan M, Smyrk T, Liu KM, et al. Histologic comparison of hereditary nonpolyposis colorectal cancer associated with MSH2 and $\mathrm{MLH} 1$ and colorectal cancer from the general population. Dis Colon Rectum 1999;42:722-6

34 Vasen HFA, Watson P, Mecklin J-P, et al. New clinical criteria for hereditary nonpolyposis colorectal cancer (HNPCC, Lynch syndrome) proposed by the International Collaborative Group on HNPCC. Gastroenterology 1999;116:1453-6.

35 Lynch HT, Smyrk T. Hereditary nonpolyposis colorectal cancer (Lynch syndrome). An updated review. Cancer 1996;78:1 149-67.

36 Rozen P, Samuel Z, Shomrat R, et al. Notable intrafamilial phenotypic variability in a kindred with familial adenomatous polyposis and an APC mutation in exon 9 . Gut 1999:45:829-33.

37 Spirio L, Olschwang S, Groden J, et al. Alleles of the APC gene: an attenuated form of familial polyposis. Cell 1993;75:951-7

38 van der Luijt RB, Vasen HFA, Tops CM, et al. APC mutation in the alternatively spliced region of exon 9 associated with late onset familial adenomatous polyposis. Hum Genet 1995;96:705-10.

39 Thibodeau SN, French AJ, Roche PC, et al. Altered expression of $\mathrm{hMSH} 2$ and $\mathrm{hMLH} 1$ in tumors with microsatellite instability and genetic alterations in mismatch repair genes. Cancer Res 1996;56:4836-40.

40 Berends MJW, Hollema H, Wu Y, et al. MLH1 and MSH2 protein expression as a pre-screening marker in hereditary and non-hereditary endometrial hyperplasia and cancer. Int J Cancer 2001;92:398-403.

41 Giardiello FM, Brensinger JD, Petersen GM, et al. The use and interpretation of commercial APC gene testing for familial adenomatous polyposis. N Engl J Med 1997;336:823-7.

42 Vasen HFA, van der Luijt RB, Slors JP, et al. Molecular genetic tests as a guide to surgical management of familial adenomatous polyposis. Lancet 1996;348:433-5

43 FriedI W, Caspari R, Sengteller $M$, et al. Can APC mutation analysis contribute to therapeutic decisions in familial adenomatous polyposis. Experience from 680 FAP families. Gut 2001:48:515-21.

44 Aktan-Collan K, Haukkala A, Mecklin J-P, et al. Psychological consequences of predictive genetic testing for hereditary nonpolyposis colorectal cancer (HNPCC): a prospective follow-up study. Int J Cance 2001;93:608-11

45 Aktan-Collan K, Haukkala A, Mecklin J-P, et al. Comprehension of cancer risk 1 and 12 months after predictive genetic testing for hereditary colon cancer. J Med Genet 2001;38:787-92.

46 Spigelman AD, Thomson JPS. Introduction, history and registries. In: RKS Phillips, AD Spigelman, JPS Thomson. Familial adenomatous polyposis and other polyposis syndromes. London: Edward Arnold, 1994:3-14.

47 Järvinen HJ, Aarnio M, Mustonen $\mathrm{H}$, et al. Controlled 15-year trial on screening for colorectal cancer in families with hereditary nonpolyposis colorectal cancer. Gastroenterology 2000;1 18:829-34. 